\title{
Severe Colchicine Poisoning: A Case Report
}

\author{
Abdelkarim Shimi, Soumaya Touzani, Ali Derkaoui, Mohammed Khatouf \\ Intensive Care Unit A1, Hassan II University Hospital, Sidi Mohamed Ben Abdellah University, Fez, Morocco \\ Email: akshimi@gmail.com
}

Received 7 September 2015; accepted 26 October 2015; published 29 October 2015

Copyright (C) 2015 by authors and Scientific Research Publishing Inc.

This work is licensed under the Creative Commons Attribution International License (CC BY).

http://creativecommons.org/licenses/by/4.0/

(c) (i) Open Access

\begin{abstract}
Background: Colchicine intoxication is uncommon but potentially life threatening because of the high toxicity of the drug. Colchicine binds to the intracellular protein tubulin, causing disturbed mitosis in all tissues followed by multi-organ failure. Case Presentation: We report a case of a 23-year-old woman admitted to emergency room 12 hours after a suicide attempt by ingestion of approximatively $40 \mathrm{mg}$ of colchicine. Few hours after consumption, first symptoms were a hemodynamic shock and ARDS, leading to her death due to multi-organ failure. Conclusion: The colchicine intoxication has strong morbidity for doses higher than $0.5 \mathrm{mg} / \mathrm{kg}$. The treatment is symptomatic. The immunotherapy using anti-colchicine allows improving critical form's prognosis.
\end{abstract}

\section{Keywords}

\section{Colchicine, Intoxication, Shock, Multiple Organ Failure}

\section{Introduction}

First isolated from Colchicum autumnale by Joseph Pelletier and Joseph Bienaimé Caventou in 1820, but falsely identified as veratrine, colchicine was only isolated as a pure and crystalline form by Alfred Houdé in 1884 [1]. It's registered for the treatment of acute gout. It's also used to treat familial Mediterranean fever, Behçet disease, sarcoidosis, psoriasis, sclerodermia and amyloidosis [2] [3]. Acute colchicines-intoxication (CI) is rare and it leads to multi-visceral failure. It has a narrow therapeutic index, with no clear-cut distinction among nontoxic, toxic and lethal doses [1]. CI severity depends on ingested doses. However, low-doses (5 - $10 \mathrm{mg}$ ) are fatal [2]. We discuss a 23-year-old patient who ingested colchicine for suicidal purpose.

\section{Case Description}

A 23-year-old woman with an unremarkable medical history came to the emergency room, 18 hours after a suicide attempt by ingestion of an estimated $40 \mathrm{mg}$ of colchicine ( $0.68 \mathrm{mg}$ per kilogram bodyweight). The symptoms were: diffuse abdominal pain, diarrhea and vomiting. On admission, her Glasgow coma scale was 15 . Her 
blood pressure was 95/57, pulse rate 125/minute. She was eupneic with oxygen saturation $98 \%$ while breating 4 litres of $\mathrm{O}_{2}$.

Gastric wash was achieved. Four-hours later, the patient presented shock state, frissons and profuse sweating. The blood pressure was 65/38 mmHg. The patient was admitted to the intensive care unit because hemodynamic instability with signs of multi-organ failure. Supportive treatment, including volume resuscitation and administration of norepinephrine and dobutamine, was started.

Laboratory results revealed a hemoglobin at $10.5 \mathrm{~g} / \mathrm{dl}$, leucocytosis of 56,000 elements $/ \mathrm{mm}$, platelets-rate of 23,700 elements $/ \mathrm{mm}$. The renal function was slightly disturbed with urea rate at $0.89 \mathrm{~g} / \mathrm{l}$, the creatinine was 25 $\mathrm{mg} / \mathrm{l}$ and the transaminase was multiplied by 2 . The prothrombin rate was $28 \%$ and the troponine 3.8. Arterial blood gas analysis showed a $\mathrm{pH}$ of 7.19 and a lactate level at $11.7 \mathrm{mmol} / \mathrm{l}$.

After 24 hours, the patient developed respiratory insufficiency due to acute respiratory distress syndrome (ARDS) and was intubated. The electrocardiogramme showed diffuse repolarization disorders. The evolution was fatal with multi-organ failure despite the considered reanimation measures.

\section{Discussion}

The colchicine is an alkaloid extracted from colchicum and Gloriosa-superb plants belonging to spindle poisons family. Colchicine has a narrow therapeutic index, with no clear-cut distinction between nontoxic, toxic and lethal doses [2]. Ingestion of more than $0.5 \mathrm{mg} / \mathrm{kg}$ of colchicine per kilogram body weight causes serious side effects and can even be fatal [2]. Lethal intoxication cases have been reported after ingestion of only $7 \mathrm{mg}$ of colchicine [4].

Colchicine is a neutral lipophylic alkaloid with mild anti inflammatory activity and strong anti mitotic activity [1] [2]. Cochicine is rapidly absorbed from the gastro intestinal tract and is rapidly distributed to all tissues [2]. The colchicine's toxicity is due to its prolonged but reversible fixation on tubulin wich, under this form, cannot be polymerized into microtubules. This property is responsible for cytostatic effect with cellular functions inhibition which is connected to inflammation mechanisms [1].

The toxic effects of colchicine occur in three stages: $1-$ Gastro intestinal phase occurring within the first few hours of ingestion which may result in volume depletion and hypotension; 2-Multiple organ failure developing after 1 - 3 days; and 3-the recovery phase in which most affected organs start to show sign of improvement by the $10^{\text {th }}$ day [5] [6].

The colchicine intoxication has strong morbidity for doses higher than $0.5 \mathrm{mg} / \mathrm{kg}$. The main symptoms are digestive disorders and decreased coagulation factors. Doses between 0.5 and $0.8 \mathrm{mg} / \mathrm{kg}$ are related to a death risk of $10 \%$ with additional medullar aplasia. Doses higher to $0.8 \mathrm{mg} / \mathrm{kg}$ are fatal with major refractory circulatory deficiency in 72 hours [7]. Our patient ingested $40 \mathrm{mg}$, which caused hemodynamic failure at first and then a multivisceral failure after 24 hours of admission.

Treatment is basically supportive. However, a recent effective experimental therapy including F $(\mathrm{a}, \mathrm{b})$ fragments of anti-colchicine antibodies was reported [8]. Colchicine specific Fab fragments consist of the light chain and variable region of the heavy chain and are derived from goats [9]. Their mechanism of action is similar to that of digoxin specific Fab fragments. There is a high affinity between the Fab fragment and colchicine and this acts to prevent the drug returning to these peripheral binding sites [10].

\section{Conclusion}

Colchicine intoxication is a life threatening condition. Colchicine binds to the intracellular protein tubulin causing disturbed mitosis in all tissues followed by multi-organ failure. The colchicine intoxication is responsible of high mortality with acute complications. The immunotherapy using $\mathrm{F}(\mathrm{a}, \mathrm{b})$ anticolchicine allows improving critical form's prognosis.

\section{Statement}

No potential conflict of interest relevant to this article were reported or known.

\section{References}

[1] Deveaux, M., Hubert, N. and Demarly, C. (2004) Colchicine Poisoning: Case Report of Two Suicides. Forensic 
Science International, 143, 219-222. http://dx.doi.org/10.1016/j.forsciint.2004.02.040

[2] Ozdemir, R., Bayrakci, B. and Teksam, O. (2011) Fatal Poisoning in Children: Acute Colchicine Intoxication and New Treatment Approaches. Clinical Toxicology, 49, 739-743. http://dx.doi.org/10.3109/15563650.2011.610146

[3] Finkelstein, Y., Aks, S.E., Hutson, J.R., et al. (2010) Colchicine Poising: The Dark Side of an Ancient Drug. Clinical Toxicology, 48, 407-414. http://dx.doi.org/10.3109/15563650.2010.495348

[4] Caraco, Y., Putterman, C., Rahamimov, R. and Ben-Cherit, E. (1992) Acute Colchicine Intoxication-Possible Role of Erythromycin Administration. Journal of Rheumatology, 19, 494-496.

[5] Stapcynski, J.S., Rothstein, R.J., Gaye, W.A. and Niemann, J.J. (1981) Colchicine Overdose: Report of Two Cases and Review of the Literature. Annals of Emergency Medicine, 10, 364-369. http://dx.doi.org/10.1016/S0196-0644(81)80239-9

[6] Levy, M., Spino, M. and Read, S.E. (1994) Colchicine: A State-of-the-Art Review. Pharmacotherapy, 11, $196-211$.

[7] Wiesenfeld, P.L., Garthoff, L.H., Sobotka, T.J., Suagee, J.K. and Barton, C.N. (2007) Acute Oral Toxicity of Colchicine in Rats: Effects of Gender, Vehicle Matrix and Pre-Exposure to Lipopolysaccharide. Journal of Applied Toxicology, 27, 421-433. http://dx.doi.org/10.1002/jat.1198

[8] Usumoto, Y., Hifumi, T., Kiriu, N., Kato, H., Koido, Y., Nishida, M., et al. (2010) Survival Case of Colchicine Intoxication Following Ingestion of a Lethal Dose. Chudoku Kenkyu, 23, 303-308.

[9] Kaplan, M.M., Alling, D.W., Zimmerman, H.J., et al. (1986) A Prospective Trial of Colchicine for Primary Biliary Cirrhosis. New England Journal of Medicine, 315, 1448-1454. http://dx.doi.org/10.1056/NEJM198612043152304

[10] Baud, F.J., Sabouraud, A., Vicaut, E., et al. (1995) Brief Report: Treatment of Severe Colchicine Overdose with Colchicine-Specific Fab Fragments. New England Journal of Medicine, 332, 642-645.

http://dx.doi.org/10.1056/NEJM199503093321004 